\title{
Mikrobiota
}

\section{Wie die Darmflora Allergien verhindert}

Der Körper jedes Menschen beherbergt eine einzigartige Kombination von Milliarden unterschiedlichster symbiotischer Bakterien, die Mikrobiota. Ein Verlust dieser bakteriellen Symbionten begünstigt die Entstehung von Allergien. Wissenschaftler des Helmholtz Zentrums München konnten dieses Phänomen in Zusammenarbeit mit Kollegen der Technischen Universität München und des Institut Pasteur aufklären und zeigen, wie die Mikrobiota auf das Gleichgewicht des Immunsystems wirkt: Die Anwesenheit der Mikroben blockiert spezifisch jene Immunzellen, die für das Auslösen von Allergien verantwortlich sind.

Der so genannten Hygienehypothese zufolge besteht ein Zusammenhang zwischen der Abnahme von Infektionskrankheiten und der Zunahme von Allergien in industrialisierten Ländern. Verbesserte Hygiene-Standards führen demnach zwangsläufig zu weniger Kontakt mit Mikroben, was mit einem erhöhten Auftreten von allergischen Erkrankungen und Autoimmunkrankheiten wie Typ-1-Diabetes einhergeht. Epidemiologische Studien haben diese Hypothese unterstrichen: Kinder entwickeln während ihres Lebens weniger Allergien, wenn sie in Kontakt mit Bauernhoftieren stehen - und dadurch auch mehr Kontakt mit Mikroben haben. Zudem zeigten experimentelle Studien mit Mäusen, dass der Einsatz von Antibiotika in den ersten Lebenstagen zum Verlust einer intakten Mikrobiota und daraufhin zu einem vermehrten Auftreten von Allergien führt. Allerdings waren die Mechanismen, die diesem Phänomen zugrunde liegen, bisher noch nicht geklärt.

\section{Darmflora entscheidend für das Verhindern von Allergien}

In einer in Science publizierten Studie zeigen das Team um Dr. Caspar Ohnmacht vom Zentrum Allergie und Umwelt (ZAUM) der Technischen Universität München und des Helmholtz Zentrums München sowie Dr. Gérard Eberl, Leiter der Microenvironment and Immunity Unit am Institut Pasteur, dass symbiotische Darmbakterien das Im-

munsystem beeinflussen und dadurch allergische Reaktionen blockieren. Um den Organismus zu verteidigen, können verschiedene Immunantworten hervorgerufen werden. Die Anwesenheit von Bakterien oder Pilzen verursacht eine Antwort von so genannten Typ-3-Zellen des Immunsystems. Diese Immun-

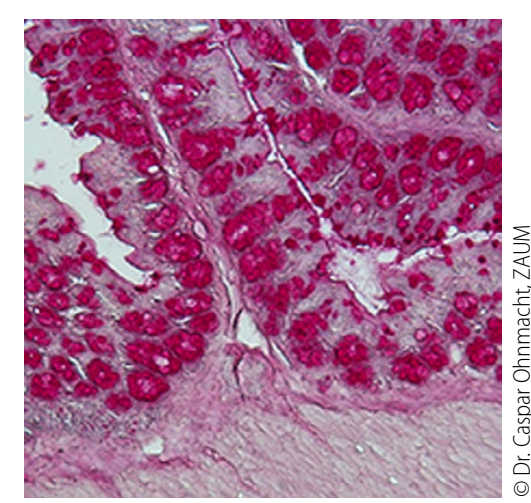

Die Mikrobiota im Darm (histologische Färbung eines Darm-Querschnitts) beeinflusst maßgeblich das Immunsystem des Wirts.

Die Ergebnisse erklären, wie ein Ungleichgewicht in der Mikrobiota eine

\section{Hier steht eine Anzeige.} 烈 Springer

zellen koordinieren dann die Phagozytose und das Abtöten der Mikroben.

Ist ein Erreger aber zu groß, um von den Typ-3-Zellen bekämpft zu werden - wie z. B. parasitische Würmer und bestimmte allergieauslösende Stoffe - ist eine andere Gruppe von Zellen für die Beseitigung verantwortlich: die Typ-2Zellen. Diese speziellen Immunzellen sind aber auch für allergische Reaktionen ursächlich. In der Studie zeigten die Wissenschaftler, dass Typ-3-Zellen, die bei einem mikrobiellen Kontakt aktiviert werden, direkt auf Typ-2-Zellen einwirken und ihre Aktivität blockieren. Somit sind die Typ-2-Zellen nicht mehr in der Lage, allergische Immunantworten auszulösen. Durch ihren Einfluss auf die Typ-3-Zellen blockiert die Mikrobiota also indirekt die Typ-2-Immunantwort, so die Forscher. überschießende Typ-2-Immunantwort auslöst, die normalerweise für die Abwehr großer Parasiten eingesetzt wird - aber eben auch zu allergischen Antworten führen kann. „Die Studie stellt einen wichtigen Meilenstein dar, um das Gleichgewicht unserer unterschiedlichen Abwehrmechanismen besser zu verstehen" ordnet Erstautor Ohnmacht die Ergebnisse ein.„Ein bisher noch unerforschter therapeutischer Ansatz für die Behandlung von Allergien und anderen Typ-2-assoziierten Erkrankungen könnte darin bestehen, ein mikrobielles Antigen nachzuahmen, um dadurch Typ-3-Zellen zu aktivieren und so auch die allergieauslösenden Typ-2-Zellen zu blockieren."

\section{hautnah $2015 \cdot 14: 47$}

DOI 10.1007/s12326-015-0165-1

Online publiziert: 13. August 2015 (c) Springer-Verlag Wien 2015
Quelle:

idw, basierend auf Ohnmacht C et al (2015) The microbiota regulates type 2 immunity through RORyt + T cells. Science, doi: 10.1126/science. aac4263 